Jiménez-Ortiz, E.A. y Jurado-Alvarán, C. (2018). El significado del territorio de San Lucas para las comunidades campesinas que lo habitan. Revista de Antropología y Sociología: VIRAJES, 20(2), 73-94. DOI: 10.17151/rasv.2018.20.2.5.

\title{
El significado del territorio de San Lucas para las comunidades campesinas que lo habitan*
}

\author{
ELIANA ANDREA JIMÉNEZ-ORTIZ** \\ CLAUDIA JURADO-ALVARÁN***
}

Recibido: 7 de agosto de 2017 Aprobado: 18 de diciembre de 2017

Artículo de Investigación

\footnotetext{
* Este artículo presenta los resultados de la investigación Zonas de Reserva Forestal de Ley $2^{\text {a }}$ de 1959: Lectura del significado de las comunidades campesinas que las habitan, requisito para optar al título de Magíster en Desarrollo Sostenible y Medio Ambiente, realizada en el marco de la Maestría en Desarrollo Sostenible y Medio Ambiente de la Universidad de Manizales. ** Especialista en Educación Ambiental y Magister en Desarrollo Sostenible y Medio Ambiente. Directora de la Corporación Grupo Trópico Diverso, Docente Tiempo Completo de la Corporación Universitaria Minuto de Dios - Seccional Antioquia - Chocó, Colombia. E-mail: elianaandreajimenezortiz@gmail.com-ejimenezor1@uniminuto.edu.co.@ORCID:0000-0001-5158-2969. Google Scholar

*** Ph.D. en Ciencias Sociales, Niñez y Juventud. Universidad de Manizales y Centro Internacional de Desarrollo Humano -CINDE-. Psicóloga, Universidad de Manizales. E-mail: cjurado@umanizales.edu. co. 응 ORCID: 000-0002-0139-1715. Google Scholar
} 


\title{
Resumen
}

El propósito central de la investigación fue comprender las representaciones y sentidos que las comunidades dan al habitar en la Zona de Reserva Forestal del Río Magdalena en el municipio de El Bagre Antioquia, corregimiento de Puerto López; a través de la perspectiva comprensivo-interpretativa de la hermenéutica utilizando las entrevistas a profundidad y los grupos de discusión como técnicas para la producción de información, aplicadas a mujeres y hombres campesinos que llevan más de 10 años viviendo en la zona. Aunque el conflicto armado causó terror con hechos como desplazamientos, intimidación, destierro, fragmentación social y desconfianza; las comunidades siguen sintiéndose pertenecientes al lugar, pues allí lograron conseguir un pedazo de tierra que consideran suyo -a pesar de la figura jurídica de reserva forestal-, cuentan con los medios de vida para subsistir, construyeron redes sociales y consolidaron un arraigo movido por la identificación con sus territorios de procedencia.

Palabras clave: territorio, conflicto social, arraigo, comunidad.

\section{The meaning of the San Lucas territory for the peasant communities that inhabit it}

\begin{abstract}
The main purpose of the research was to understand the representations and meanings that communities give to inhabit the Forest Reserve Zone of the Magdalena River in the municipality of El Bagre, Antioquia, in the village of Puerto López, through the comprehensive-interpretative perspective of hermeneutics using in-depth interviews and discussion groups as techniques for the production of information applied to peasant women and men who have been living in the area for more than 10 years. Although the armed conflict caused terror with events such as displacement, intimidation, exile, social fragmentation and distrust, communities still feel belonging to that region because there they managed to get a piece of land that they consider theirs despite the legal status of Forest Reserve it has. They have the means to subsist, built social networks and consolidated a rooting moved by the identification with their territory of origin.
\end{abstract}

Key words: territory, social conflict, rooting, community. 


\section{Introducción}

I propósito central de la investigación fue comprender las representaciones y sentidos que las comunidades le dan a estos territorios, particularmente a la Zona de Reserva Forestal del Río Magdalena en el municipio de El Bagre Antioquia, corregimiento de Puerto López ${ }^{1}$.

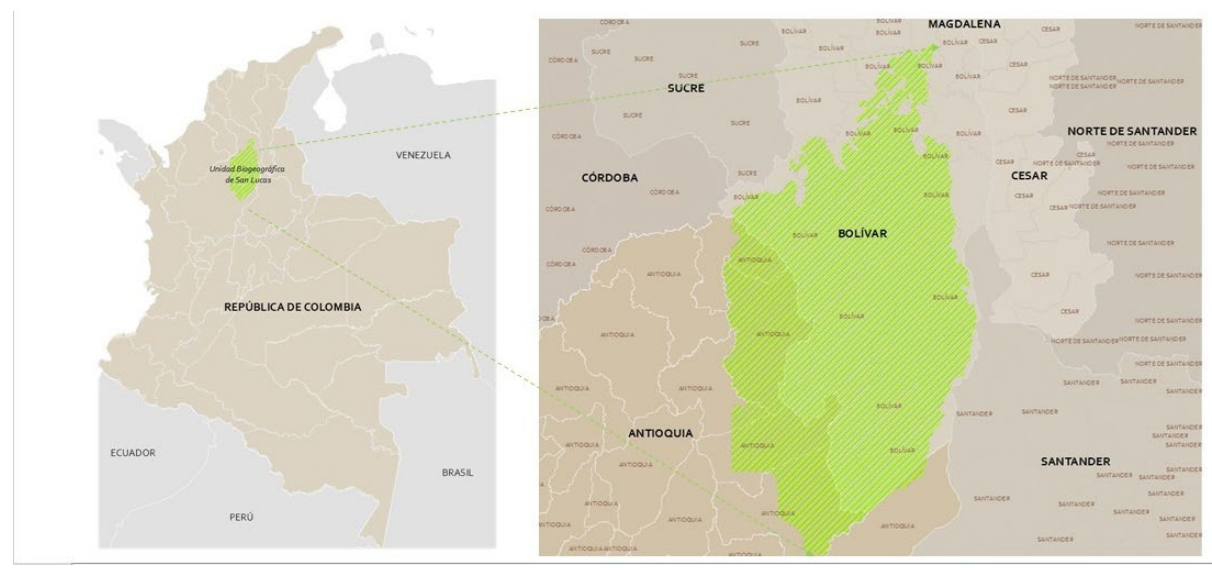

Gráfica 1. Zona de Reserva Forestal del río Magdalena - Colombia Fuente: Corporación Grupo Trópico Diverso

\footnotetext{
${ }^{1}$ Entre los años 2008 y 2014 la Corporación Autónoma Regional del Centro de Antioquia CORANTIOQUIA- adelantó el proceso de ordenación forestal de la zona de reserva forestal del río Magdalena de la Ley $2^{a}$ (1959) en el Bajo Cauca y Nordeste antioqueños. En el desarrollo de este proceso se identificaron algunos elementos identitarios de la construcción territorial dentro de la unidad biogeográfica en mención, los más relevantes fueron: Las comunidades campesinas no son dueñas formales de las tierras que habitan, debido a que los terrenos de las ZRF son baldíos, cuya propiedad es del Estado, lo que implica que si las comunidades campesinas quisieran formalizar la tenencia de la tierra, primero deben tramitar la sustracción de la reserva forestal, y luego iniciar los procesos de adjudicación de baldíos ante la Agencia Nacional de Tierras, antiguo Instituto Colombiano de Desarrollo Rural-INCODER-. Por su riqueza en recursos naturales, esta ha sido una zona en constante explotación que la lleva a una creciente deforestación y disminución de las fuentes hídricas, de la fauna y de especies forestales nativas; ha sido en un corredor estratégico para los grupos armados, lo que ha provocado la disputa territorial entre ellos (CORANTIOQUIA, 2013).
} 


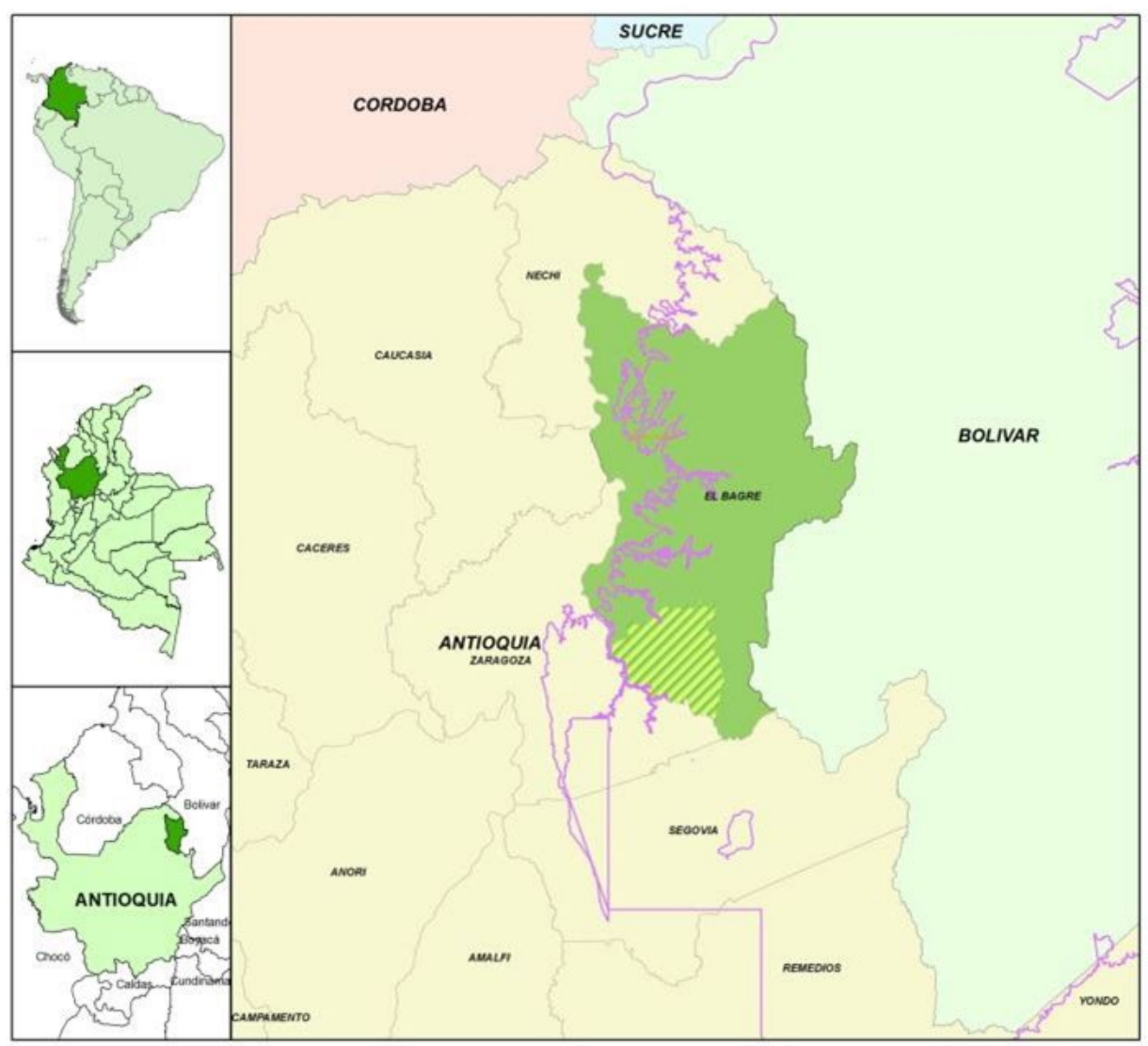

Gráfica 2. Municipio de El Bagre, Corregimiento de Puerto López Fuente: Corporación Grupo Trópico Diverso

Si bien puede pensarse en las Zonas de Reserva Forestal como unidades geográficas que determinan unos usos permitidos a la región en ellas contenidas, ello por sí solo no está dando cuenta de un territorio. Nates (2010) plantea que "Referirnos al territorio no es lo mismo que referirnos a la tierra, y por tanto, no se puede medir ni contar; él es una significación y por ello para asirlo lo nombramos y vivimos" (p. 210). El espacio físico (Nates, 2011) es el lugar para hacer y en donde se vive físicamente, que contiene los medios para desarrollar la vida de las personas que lo habitan y que lo significan, y en cuya transformación lo territorializan, "los sentidos de identidad, de participación (ser parte) y de pertenencia, son algunas de las maneras a través de las cuales experimentamos o sentimos -valga la redundancia- la sensación del territorio" (Wilches Chaux, 2006, p. 15). 
La pregunta orientadora de la investigación fue: ¿qué significa el territorio para las comunidades campesinas que habitan los bosques declarados como Zonas de Reserva Forestal del Río Magdalena, Bajo Cauca antioqueño, municipio de El Bagre, corregimiento de Puerto López? De esta, se desglosaron categorías de análisis como las percepciones, usos, prácticas y relaciones de las personas que habitan en la Zona de Reserva Forestal -ZRF- ya que el "territorio se constituye en una construcción cultural" (Nates, 2011, p. 211), en el que tienen lugar las prácticas sociales con intereses y percepciones distintos, valoraciones y actitudes territoriales diferentes, que generan relaciones de "complementariedad, reciprocidad y de confrontación"; esto se realizó, con un criterio hermenéutico (Ángel y Herrera, 2011), interpretando las narrativas de las personas que viven el día a día construyendo, transformando y definiendo un lugar con unas características establecidas desde la legislación, como su territorio, pues "una de las maneras de objetivación del ser humano para transformarse en sujeto es como hablante" (Jimeno, 2016, p. 7).

En la forma seleccionada para presentar los resultados, prima la palabra de aquellas personas que participan en la construcción del territorio de San Lucas a través de su propia experiencia de vida, relacionando las categorías de análisis con aquellos descriptores que dan cuenta de la construcción social e histórica del territorio como lo son lo cultural, lo económico y lo sociopolítico, al entender que el territorio no tiene una única forma de mirarse, es una construcción multidimensional en donde convergen las relaciones de poder, la valoración y construcción simbólica que se le atribuye y la económica que está determinada por la consecución de recursos y la relación capital - trabajo como producto de la división territorial del trabajo (Haesbaert, 2011).

\section{El arraigo}

La identidad cultural con el territorio trae consigo el arraigo en una dimensión cultural: es el ámbito al cual se vincula la creación y recreación de cultura e identidad y donde el sujeto o los sujetos de la cultura se lo apropian simbólicamente, lo hacen parte de su propio sistema cultural, de su sentido de pertenencia socio-territorial, en donde el territorio les pertenece y en donde se pertenece al territorio. "Esto es así en tanto el ser colectivo se relaciona íntimamente a la forma de organización social propia y localizada: comunidad, familia, pueblo; es decir, al arraigo territorial de la cultura, de la identidad, del yo colectivo" (Sosa, 2012, p. 100). 
Para hablar de arraigo, es preciso hablar de desarraigo y de despojo del territorio que, como lo plantea Sánchez (2014):

No es sólo la pérdida de un pedazo de tierra "también se convierte en la anulación de todos esos espacios subjetivos en los cuales había devenido alguien en virtud de pertenecer a algún lugar y de aparecer frente a algunos otros. (p. 18)

Además, como dice Gaviria (2014), la situación vivida por las personas va más allá de un desplazamiento, que es moverse de lugar. Lo que se ha vivido en el país es el destierro, como lo propone Beatriz Restrepo (como se citó en Gaviria, 2014):

Siempre he sentido alguna incomodidad epistemológica y moral con el termino en uso, desplazamiento, que a mi entender no hace justicia ni en lo político, ni en lo social, ni en lo moral, a la gravedad del fenómeno que padecemos, al reducirlo según el concepto que de él hacemos, a un mero cambio de lugar. Más adecuado en todo sentido me parece el concepto de destierro que nombra plenamente aquello que está sucediendo entre nosotros, la privación del referente a la tierra de arraigos y la expulsión de un territorio al que se siente pertenecer, por agentes privados por fuera de la legalidad y por métodos violentos de amedrentamiento y daño físico. (p. 48)

El conflicto dejó un territorio con personas desterradas que nunca perdieron sus vínculos vitales con él, con su cultura y con la comunidad a la que pertenecen, el destierro no trajo consigo el desarraigo que, en palabras de Gaviria (2014), es una "condición identitaria que no permite encontrar posibilidades en la construcción de nuevas interacciones y significaciones en los lugares de llegada (p. 54)". Por el contrario, lo que para los habitantes de San Lucas es que "no caben" en otros lugares.

\section{Precisiones metodológicas}

La hermenéutica es un criterio epistemológico para abordar el método. Esta perspectiva abre la posibilidad de abordar las metodologías provenientes de las ciencias sociales para introducir en ellas nuevas formas que despejen su orientación epistemológica (Ángel, 2012).

La hermenéutica es una filosofía del conocer humano que elimina el dualismo sujeto-objeto, demostrando que el método hace énfasis en el diálogo como forma de conocer lo humano (Ángel y Herrera, 2011), ubica los métodos en su lugar, como ayudas para el conocimiento, no como su 
criterio de validez (Herrera, 2009).

En el abordaje de estudios sociales desde la perspectiva comprensivointerpretativa, la comprensión entendida como la fusión de dos perspectivas: la del fenómeno que se aborda y la del intérprete, ubicados en su vida, en su cultura y en los momentos históricos propios (Martínez, 2004); comprender los significados implica, comprender los detalles que se presentan como descriptores del fenómeno, lo que implica familiaridad con él, conocer su contexto histórico, los actores involucrados y las dinámicas que allí se desarrollan, aspectos que son ya interpretación.

La investigación, entonces, realizó trabajo de campo etnográfico orientado desde "técnicas discursivas para la producción de información en la que prima la voz y el relato de quien habla inmerso en las formaciones y convenciones discursivas de su tiempo y lugar" (Jimeno, 2016, p. 10), pues su entorno sociohistórico es el que aporta para su propia construcción narrativa y va más allá, moldeando un discurso permeado por las condiciones particulares del contexto.

Las técnicas empleadas para la producción de la información fueron entrevistas en profundidad y grupos de discusión. Las entrevistas se realizaron con 11 campesinos/as, de las cuales cuatro fueron mujeres y siete fueron hombres, que habitan en las veredas de Caño Claro, La Bonga, El Alto del Berrugoso, Villa Hermosa, Dos Bocas, Villa Grande y La Capilla del corregimiento de Puerto López desde hace 10 años los más recientes y otros desde hace 40 años, en un momento histórico, década del 2000. La gran mayoría tuvo que desplazarse como consecuencia del conflicto armado, que consideran esa tierra como suya pero que no poseen la tenencia formal debido a la in-adjudicabilidad de terrenos baldíos. Además de las entrevistas, se realizó un grupo de discusión con cinco líderes comunitarios que se agrupan a través del "Colectivo de Comunicaciones por el Derecho a la Tierra", conformado por campesinos, negros e indígenas habitantes de las veredas de Caño Claro, La Bonga, El Alto del Berrugoso, Villa Hermosa, Dos Bocas, Villa Grande y La Capilla en el que se presentaron los resultados del momento de recolección de información, se plantearon inquietudes, se retroalimentó y validó las interpretaciones hechas. El proceso de registro, sistematización y análisis de la información se realizó a través de la transcripción, elaboración de matrices categoriales que orientaron el proceso de interpretación y comprensión. 


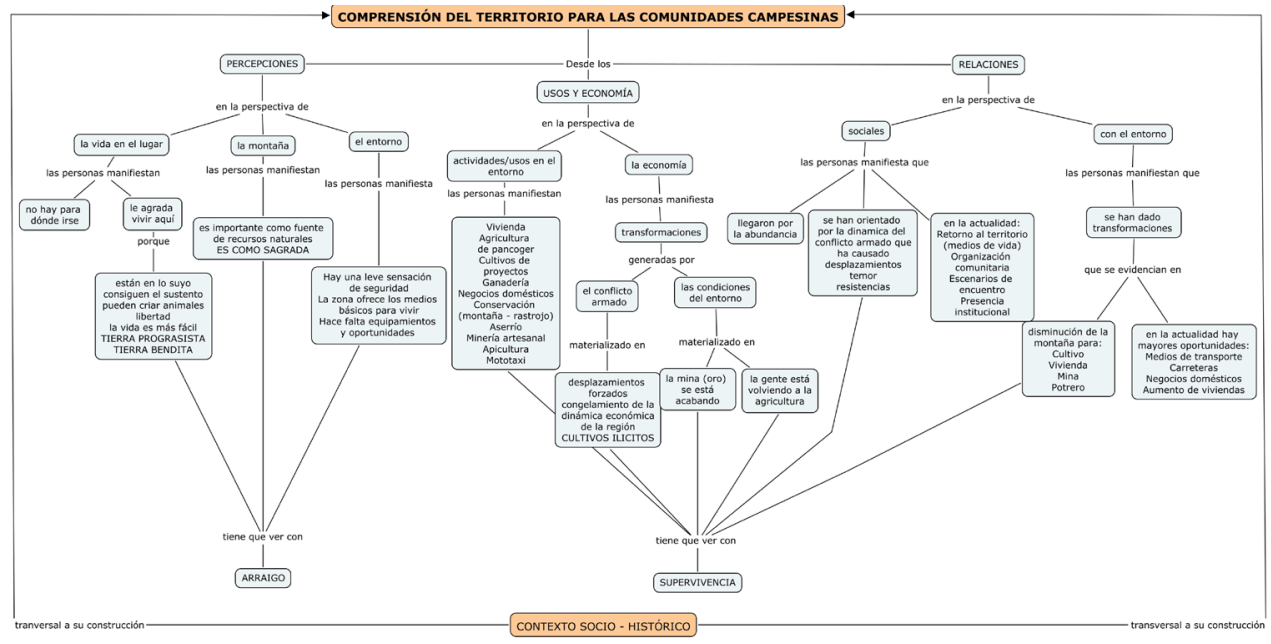

Grafica 3. Matriz categorial Fuente: Elaboración propia

La construcción de estas matrices permitió configurar categorías emergentes como el arraigo, el sentido de pertenecer y de vinculación simbólica con el lugar y la supervivencia, donde el lugar es el soporte económico para la satisfacción de las necesidades básicas de sus habitantes.

\section{Resultados}

\section{Las dimensiones del territorio en el pensar territorializado}

"El territorio se construye a partir de un proceso de construcción social que da sentido a un espacio" (Echeverría y Rincón 2000, p. 22); en este sentido éste tiene una doble connotación, tanto como soporte material o "contenedor" que sirve de base para la vida de las sociedades y, como proceso de construcción social que se da gracias a la interacción social y de ésta con el entorno natural, siendo una construcción mediada por las complejidades propias de la historia, de los intereses particulares, lo político, lo económico e incluso lo cultural.

"El territorio no es unívoco" (Nates, 2011), se determina a partir de la óptica desde la cual sea estudiado, bien sea como soporte material o como objeto de estudio, que es el caso presente, en el que su proceso particular de poblamiento, los acontecimientos sociales, las dinámicas políticas y 
económicas lo han configurado en sí de un modo particular, más allá de una figura legal de unidad geográfica, es un territorio cargado de "contenidos y de permanentes transformaciones" (Sosa, 2012, p. 15), influenciadas por la toma de las decisiones, o la omisión de ellas, de los actores involucrados en las dinámicas específicas del mismo.

Haesbaert (2011) propone que “además de las perspectivas materialistas en la que el territorio es una realidad existente $\mathrm{y}$, de la naturalista en la que se confiere al territorio la 'apropiación simbólica'" (p. 64), puede hablarse desde una perspectiva integradora en la que su mirada debe superar la perspectiva estrictamente material o simbólica, esta debe también incorporar el análisis desde lo natural, lo político, lo histórico, lo económico y lo cultural, permitiendo una visión articulada, no necesariamente totalizante, pero sí que permita tener panoramas más amplios que faciliten la lectura y comprensión de las dinámicas desarrolladas.

Así pues, el territorio desde el pensar territorializado, presenta los resultados obtenidos con la investigación, desde la voz de las personas que allí habitan y lo hablan desde su percepción de vivir en el lugar, de los usos que hacen del mismo y, de las relaciones sociales que allí se construyen, en últimas la apropiación del mismo desde la perspectiva de multidimensionalidad del territorio, siguiendo a Haesbaert (2011) "éste se define con referencia a las relaciones sociales (o culturales, en sentido amplio) y al contexto histórico en el que está inserto" (p.67), hablar del significado del territorio para las personas que habitan la $\mathrm{ZRF}^{2}$ del río Magdalena, implica partir de su constitución y construcción histórica que data aproximadamente de la década de los años 50 del siglo XX hasta el año 2015, ya que esto define precisamente la identidad y el valor que sus habitantes le confieren al mismo, determina sus representaciones, sus usos y sus acciones que en términos de lo político instauran como actores en la construcción territorial. El proceso de contrastación con lo ya escrito a partir de las dos miradas permitió comprender que las categorías emergentes expresaban la construcción social del territorio en su complejidad (Arboleda, 2007).

Estas categorías se concatenan con las dimensiones del territorio ampliamente abordadas en textos de base como Haesbaert (2011), Nates (2011), Sosa (2012) pues le dan contenido y sustento a estas últimas. La Figura 4 esquematiza la relación que se hizo entre las categorías que dan cuenta del significado del territorio y cómo, la voz de sus habitantes muestra una articulación entre éstas con las dimensiones del territorio, abordado desde la perspectiva integradora de Haesbaert (2011).

${ }^{2}$ ZRF: abreviatura de Zona de Reserva Forestal. 


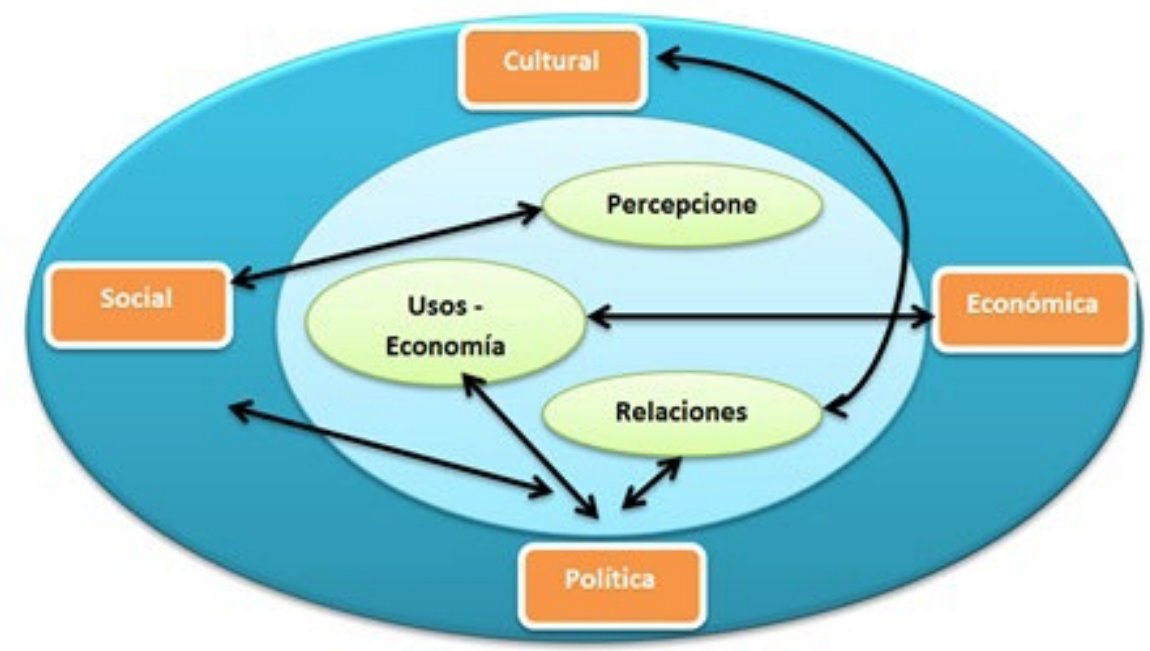

Gráfica 4. Lectura del significado del territorio de San Lucas Fuente: Elaboración propia

\section{Perspectiva socio - histórica de la territorialización de San Lucas}

Propongo la escritura de este aparte a través de la desterritorialización, como concepto construido y desarrollado inicialmente por Félix Guattari y Gilles Deleuze, en el que plantean que en todo territorio existen momentos de tránsito o en sus términos la "desterritorialización que es el movimiento por el cual se abandona el territorio y la reterritorializacion como el movimiento de construcción del territorio" (Haesbaert, 2011, p. 106); ello implica un referente inicial de territorio como acto de construcción colectiva y con base en ese referente se dan procesos de desterritorialización o "Líneas de fuga" que involucran movimientos, desacomodos y cambios de los territorios para llegar a la re-territorialización que, como lo plantean los filósofos, tomando a Haesbaert como referente documental, es construir nuevamente el territorio, no volver al territorio anterior sino uno transformado.

El devenir socio histórico de la construcción social de este territorio puede pensarse en tres momentos, el primero la llegada de personas, el segundo el conflicto armado y el tercero el regreso o momento actual. En el primer momento, la llegada al territorio, García (como se citó en CORANTIOQUIA, 2013) señala que: 
(...) la dinámica regional del Bajo Cauca es el resultado del llamado proceso de colonización de territorios vacíos que se incorporaron al espacio productivo nacional. Esto fue resultado de los cambios en el modelo de desarrollo en la segunda mitad del siglo XX y de los nuevos rumbos que fue tomando la economía del país; que en el caso del Bajo Cauca, constituye un lugar estratégico para la articulación de la red vial del país así como para la explotación de recursos mineros. (p. 60)

Las personas se movilizaron por la riqueza natural, especialmente minerales, como el oro, lo que hacía de ese lugar una tierra prometida para conseguir dinero, salir de aprietos financieros, regresar a sus lugares de origen y establecer una familia.

vea vine... ¿Usted sabe por cuánto vine yo aquí? Por 3 meses, por toda la cantidad de tiempo que llevo yo aquí, vine a ganarme una platica porque me iba a casar... Y me casé fue aquí... ¡Y encontré trabajo claro! Encontré trabajo, me puse a trabajar y me quedé trabajando ahí. Ahí trabajaba, en ese entonces trabajaba machetiando, desmontando potreros, haciendo cosechas en otras fincas, yo no tenía nada, el pedacito de tierra que ahora sí es mío, me lo conseguí fue trabajando en esa finca que era del difunto Jaime Patiño trabajé ahí 15 años, ahí me conseguí esto, y acá estoy. (Entrevista de campo No. 2, abril de 2015)

Ilusión por tener mayores oportunidades de trabajo para quienes no tuvieron la oportunidad de capacitarse, gracias a la abundancia en recursos naturales y a la poca población asentada en la zona, esta se hizo atractiva para el "trabajo material" abriendo monte y jornaleando en fincas cuidando los potreros y extrayendo madera y oro, algunas personas llevan más de diez años de haber llegado a la zona, y otras cuarenta, treinta, veinticinco años, durante los cuales han conformado sus núcleos familiares, algunos han conseguido tierra y han trabajado especialmente en la agricultura de pan coger, cría de animales para el sustento familiar, cultivos de proyectos productivos (caucho, cacao, rastrojeras, silvopastoreo), potrero con animales, tiendas de víveres en las casas, aserrío, piscicultura, minería, como ocurrió en varios lugares del territorio (Biorred, 2014).

La cosa es que la gente que se traslada a poblar San Lucas en esta zona no son conscientes de lo que hacían, simplemente la atracción era el tema del oro y el tema tierras, y por qué el tema tierras, porque eran indígenas, en su mayoría o poblaciones negras de Bolívar, Sucre y Córdoba y la cosa allá de la concentración de la tierra de los terratenientes (en esas zonas mencionadas) o sea, paulatinamente 
se iba dando un despojo en tanto la concentración de la ganadería, entonces, esa gente iba vendiendo (los que se vinieron para San Lucas) y cuando vendían no eran capaces de subsistir sin ese modelo económico de ellos, (...) Entonces, en el boom de San Lucas, migran acá... (Grupo de discusión, julio de 2015)

El segundo momento ocurre durante las décadas de los noventa y dos mil, cuando el conflicto armado se agudiza por la presencia de los grupos paramilitares. Aunque los procesos de construcción territorial de San Lucas han estado marcados por la presencia de actores armados como las FARC - Fuerzas Armadas Revolucionarias de Colombia-, ELN -Ejército de Liberación Nacional- y en su momento AUC -Autodefensas Unidas de Colombia-, que disputan la apropiación del territorio por todas sus bondades físicas y que, en la búsqueda de apropiación territorial se valen del terror y confrontación armada ocasionando fracturas en las dinámicas sociales, culturales, políticas, económicas y ambientales (UARIV, 2014) ${ }^{3}$.

A partir del 2006 se da la reterritorialización, en la que se viene tejiendo una relación de reconocimiento de la importancia de la montaña, su aporte para el desarrollo de la vida en el lugar, su cultura campesina sobre las actividades que allí se desarrollan, la necesidad de utilizar el bosque sin acabar con él y una transición a actividades económicas complementarias con el bosque, en un marco de construcción colectiva y solidaria en el que reconocen que el conflicto, a pesar del daño y el dolor, les permitió ser visibles ante las instituciones, mostrar sus condiciones de vida, sus necesidades, sus potencialidades, sus sueños y su arraigo a la tierra.

Es valioso el acompañamiento de las instituciones públicas, privadas y de cooperación internacional, que se materializan en temas de asistencia técnica para el desarrollo de proyectos productivos de corto y mediano plazo, asistencia psicosocial para la reparación colectiva y para construir el tejido social, la promoción de la ciudadanía, han permitido un diálogo (Fundación Ideas para la Paz [FIP], 2014). Esto ha propiciado la reconstrucción del tejido social y tradiciones como la vara de premios, la celebración del día del campesino, de la semana santa, campeonatos de fútbol, el reconocimiento de las potencialidades productivas del bosque,

\footnotetext{
${ }^{3}$ Los años noventa son el preámbulo de la violencia que se va a desatar en la década del 2000, la economía coquera llega a la región y los grupos insurgentes van a ver en esta una oportunidad para financiar su proyecto armado. Algunos campesinos comienzan a ensayar con la coca, pero este es un negocio camuflado y aun no tiene un mercado importante. (...) Masacres, asesinatos, desapariciones amedrentamientos acaban definitivamente con las juntas de acción comunal (JAC), con asociaciones comunitarias, cooperativas, comités, líderes y hasta con las escuelas que eran la única presencia del municipio en las veredas. Esto ha repercutido en los patrones de vida, le pérdida de valores de confianza, solidaridad y comunitarismo que se habían construido con esfuerzo (CORANTIOQUIA, 2013, p. 61).
} 
la organización comunitaria para la participación y para la asociatividad empresarial, el empoderamiento de la mujer y la emancipación ciudadana en la lucha simbólica y material por la apropiación del territorio.

Para las personas que lo habitan, San Lucas es su territorio en el que obtienen el sustento y en donde han logrado asociarse de manera solidaria, donde han encontrado rasgos culturales similares a los de sus lugares de origen y donde han establecido los rasgos culturales que los definen como sus habitantes.

\section{La percepción de vivir en San Lucas}

Las percepciones hablan de las impresiones, la idea o valoración que las comunidades le dan al territorio, en este caso particular, facilitan la articulación con la dimensión social, estableciendo relaciones y conexiones con la historia vivida y las condiciones de contexto sociales, políticas o culturales (Sosa, 2012); los grupos humanos son quienes definen las estructuras de sus sociedades, como resultado de los intercambios económicos, procesos de poblamiento, movilidad, construcción de identidades y conflictos, los cuales darán cuenta de su apropiación o sentido de pertenencia y su participación en la vida comunitaria.

En el caso de San Lucas, marcada en un momento importante por las consecuencias del conflicto armado, las personas deciden regresar y construir nuevas formas de vivir y habitar, estar allí les agrada, se sienten en lo suyo, les da tranquilidad, libertad y la posibilidad de obtener alimento y producir algunos ingresos que faciliten solventar la vida. Es un territorio proveedor que, en términos de Imbach (2012) les permite obtener los medios de vida, es decir, el desarrollo de actividades para satisfacer sus necesidades básicas

Pues sí... Pues porque, por lo mismo, aquí la vida es más fácil pa' uno, porque en otra parte la vida es más dura.

La ciudad no, ni las conozco, Ni al Bagre casi voy, y ahora enfermo ¡Menos!. (Entrevista de campo No. 2, abril de 2015)

La cruenta historia que se ha escrito en la página del conflicto armado en la región también ha transformado los modos de relación de las personas entre sí, con el entorno natural y con las dinámicas económicas que se venían desarrollando antes de la década del 2000, momento en el que ingresan los grupos paramilitares. 


\section{La economía como motor de transformaciones}

No es posible hablar de economía como un asunto independiente de las dinámicas que se desarrollan en un contexto particular, pues el territorio actúa como un ámbito de producción, intercambio, distribución y consumo, que hace parte de la construcción social y de las relaciones de poder que se forman a partir de sus potencialidades (Ángel Maya, 1997).

En el contexto territorial estudiado, lo económico como formas de solventar las necesidades humanas a través de la siembra y la comercialización, hay una relación directa entre tierra y base económica, ya que la primera se constituye en la segunda, pues no hay otras alternativas económicas, la tierra entonces se convierte en el patrimonio más importante de las familias campesinas, permite cultivar el alimento familiar y extraer recursos maderables y auríferos para la venta y sustento de otras necesidades, si bien para Haesbaert (2011) la dimensión económica no debe ser la única que defina el territorio; Milton Santos (como se citó en Haesbaert, 2011) pone la economía como un "refugio, buscando constantemente adaptarse al medio geográfico local, a la vez que recrean estrategias que garanticen su supervivencia en los lugares" (p. 51). Esta situación, evidentemente, ocurre en San Lucas, los medios económicos juegan un papel fundamental en la construcción de territorio, pero no es un medio independiente totalmente de las demás dimensiones, se encuentra estrechamente ligada a las dinámicas políticas y las decisiones que se toman desde los actores externos e internos, pues estas inciden directamente en las dinámicas cotidianas.

Muchas personas que llegaron al municipio de El Bagre, lo hicieron con la ilusión de lo que les podía significar la abundancia de riqueza natural, especialmente el oro y la dinámica que se suscitaba entorno del mineral: la venta de mercancía, la arriería hacia Guamocó, tumbar monte, la producción agrícola para la venta. Sin embargo, con la disputa por el territorio de los grupos armados (FARC, ELN y AUC), entre 2000 y 2006 se agudizó la violencia, e hizo más profundas las transformaciones en la dinámica económica:

Una vez pasa el 2000, la gente se queda sin sustento económico y quizá sin alimento, porque la crisis fue muy fuerte, y la cosa es que, en el 97 empiezan los cultivos ilícitos cierto, los cultivos ilícitos lo que hacen es que llegara mucha gente externa al territorio y los locales se dedicaran a trabajarle a esos externos, entonces se abandonaron todo lo que fue cultivo de pan coger y entonces terminaron también teniendo cultivos ilícitos. Entonces el cultivo ilícito no les permitía, eso era un círculo vicioso, no permitía realmente, descansar o tener tiempo para otras actividades y lo que generaba alcanzaba para comprar lo del sustento 
alimentario el territorio se convirtió dependiente, realmente de lo que entraba, el sustento alimentario y toda esa situación. (Grupo de discusión, julio de 2015)

Las transformaciones territoriales han estado marcadas por las dinámicas propias de los yacimientos de oro. Además, es un corredor estratégico entre el oriente y el occidente del país, que lo hace atractivo para su conquista por los grupos armados ya mencionados. La ausencia del Estado ha facilitado el asentamiento de estos grupos en la zona, la economía se congeló, pues los desplazamientos hicieron que el territorio se quedara vacío y no había a quién venderle los productos agrícolas.

Te digo que, ahora mismito yo, me sostengo del pasto (...) Alquilo, arrendo pasto, pero ya ahora, está grave la cosa porque es que ya, la minería se acabó, mejor dicho, por allá montaron una máquina ${ }^{4}$, unas ventas de combustible o una morroca que lleva combustible pa' allá y se quedaron las mulas, mucha mula que quedó parada, aquí yo le arrendaba a este señor que vive aquí que le dicen el pastuso, tenía 50 mulas, aquí las arrendaba donde mí, ya se va, ya está recogiendo (...) La morroca es una cosa que tiene las esteras como si fuera una retro, dentra combustible hasta allá, allá tienen tanques y todo eso, entonces esos fletes están creo que como a \$30.000... Acabó con la arriería, mejor dicho (...). (Entrevista de campo No. 2, abril de 2015)

Los campesinos buscan otras oportunidades $y$ formas de relacionamiento con su entorno y para ello reclaman dignificar sus vidas con oportunidades, proyectos productivos y comercialización segura, creación de escuelas, reactivación del centro de salud, fuentes estables de ingresos, seguridad vial, legalización de sus JAC, legalización de la tenencia de tierras.

En un momento fueron obligados a dejar la agricultura, y ahora están volviendo a ella, como una forma de obtener sus alimentos y de generar redes de comercio local. Lo que viene ocurriendo puede llamarse arraigo, re-construcción social del territorio, reterritorialización, pero lo que muestra es que son personas que han regresado a este lugar, a pesar de las condiciones de miseria, porque no caben en otro lado. (Grupo de discusión, julio de 2015)

\footnotetext{
${ }^{4}$ Cuando la persona de la entrevista habla de “(...) pa' allá montaron una máquina”, se está refiriendo a la zona conocida como Guamocó.
} 


\section{Las relaciones, como un ejercicio de poder}

Las circunstancias que hasta ahora se han presentado, describen la construcción de relaciones entre las personas y de ellas con el entorno, definiendo al territorio, como un escenario político de construcción y confrontación. En términos de Mario Sosa (2012):

La dimensión política se refiere al ejercicio de poder que se traduce en constantes y complejos procesos y dinámicas de lucha por la posesión y control del territorio que, a su vez, se convierten en apropiaciones, construcciones y transformaciones territoriales. Alude, asimismo, a un escenario de relaciones de dominio y ejercicio de poder que se constituye en uno de los límites de posibilidad -en términos de Bozzano para pensar y proyectar al territorio en función de determinados intereses, lo que define su evolución o transformación en cuanto constructo social. (p. 71)

En esa lucha de poder por la apropiación del territorio, especialmente la de los actores armados, se ven implicadas las comunidades campesinas, que son víctimas, a través de expresiones de violencia en desgarradores hechos victimizantes ${ }^{5}$, que han marcado momentos históricos de su configuración social por esas comunidades que encontraron allí, un lugar que les permitía construir vínculos sociales, parentales y ambientales (Wilches Chaux, 2006).

La lucha territorial marcada por la violencia y el temor fue devastadora para las comunidades que allí viven, y esto los movilizó para saber que la construcción de su territorio es posible:

Cambiaron los modos de relación entre nosotros a partir del conflicto, yo pienso que sí cambió, pero para bien, ha mejorado porque ya no nos miramos como la familia, el vecino o el que vive ahí, sino que ya estamos mirando más allá de nuestra comunidad. En esa época, la gente se reunía como Junta de Acción Comunal por ejemplo, y era muy puntal en las reuniones y había menos presencia institucional, sin embargo, la gente se sostenía la JAC. Cuando el conflicto más fuerte, eso se rompe (...) permanece en la conciencia de la gente. Hoy yo digo que ha mejorado, que todos los líderes manejan una relación

\footnotetext{
${ }^{5}$ En la recolección de información para la elaboración del diagnóstico del daño, las comunidades, representadas en el Comité de Impulso, describen algunos hechos victimizantes ocurridos en la década del 2000: fueron combates, destrucción y apropiación de bienes protegidos, desplazamientos forzados, violaciones, mutilaciones, asesinatos, desapariciones forzadas, reclutamiento forzado, amenazas, torturas, masacres, limitación de la movilidad, obstrucción de la organización comunitaria, negación de acceso al puesto de salud, a la escuela, a la movilidad, al alimento, a la vivienda.
} 
de toda la región, que las mismas comunidades, los programas han llegado a integrar unas comunidades con otras y eso es bueno (...). (Grupo de discusión, julio de 2015)

“En sí la guerra hizo cambiar muchas cosas, porque por la violencia es que han ido entrando las instituciones a las comunidades" (Grupo de discusión, julio de 2015).

\section{¿Qué es San Lucas para las comunidades campesinas que lo habitan?}

"Territorio es ese pedazo de tierra donde yo tengo mi ombligo enterrado". Hermes Fidel González. Vereda Villa Grande, julio de 2015.

No es su territorio por ser ZRF. Esta es una figura jurídica con implicaciones en la tenencia de la tierra (Ríos y Sanclemente, 2014). Las personas que llegaron no lo hicieron movidas por la reserva forestal, sino por la falta de tierras en otros lugares, como refugio de la guerra en otras regiones; más allá de una figura jurídica, la unidad biogeográfica de San Lucas es el territorio que habitan:

Bueno lo que yo puedo entender es que no se tenía esa percepción de que era más barata porque era baldío o reserva forestal, la gente quizá no manejaba eso, incluso el campesino tradicionalmente ha manejado ahora el asunto de tenencia y de legalización es más por una exigencia del banco, (...) en esa época era la Caja Agraria, lo que existía y prestaba plata como con la cédula o algo así, no había que presentar un documento legal de la finca. Entonces, eso le hacía a la gente, que como estaba más o menos cerca y era un territorio para coger, no era para irle a comprar, entonces cuando llegaban se daban cuenta de que habían personas que tenían un globo de monte que no le interesaba sino vender porque yo llegué primero y cogí 500 hectáreas pero yo no voy a trabajar esas 500 hectáreas, yo las cogí para irlas vendiendo a los que vayan llegando, entonces por eso el tema del precio era muy barato pero no tenía nada que ver con la reserva forestal. (Grupo de discusión, julio de 2015)

La categoría de reserva forestal se comprende en el marco territorial cuando empiezan las transacciones comerciales de la tierra, pues al ser reserva con terrenos baldíos propiedad del Estado, son inadjudicables para las comunidades campesinas, lo que trasciende el debate sobre los derechos de los campesinos en ZRF (Vélez, Correa y Ríos, 2010), y la falta de garantía 
para su goce efectivo al vulnerarse el derecho fundamental a la vivienda y al territorio a familias que se han arraigado en él desde hace cerca de 50 años y que han resistido a los embates del conflicto armado. Frente a la pregunta sobre la incidencia de Reserva Forestal de la Ley $2^{\underline{a}}$ (1959), esto es lo que los campesinos expresan:

Yo diría que tiene incidencia ahora 6 años hacia acá, es que viene a tener una incidencia en la conciencia de la gente, pero la gente aquí llegó sin interesarle si era reserva o no y a eso se le sumó que cuando ellos empiezan a querer legalizar esas tierras, la gente lo que le decía era se le va a reconocer lo que tiene en tumba, que es la mejora, entonces la gente vivió contenta con sus mejoras ... y se tumbó la selva incentivado por esa premisa (...) por lo menos, si usted tenía como 10 hectáreas de tumba tenía derecho a no sé cuantas de montaña, entonces la gente vivía tumbando porque tenía derecho de más montaña para tumbar. (Grupo de discusión, julio de 2015)

\section{Discusión}

El devenir histórico de la construcción territorial no es un asunto aislado al análisis y la puesta en evidencia de la interacción de las dimensiones del territorio, en la historia misma, en el transcurrir del tiempo es que se construye el territorio, una concepción y una experiencia de vida en constante transformación.

La territorialización de San Lucas se dio gracias a la disponibilidad de recursos naturales y de tierras para distribuir entre las personas que llegaron provenientes de otras regiones del país, desde ese momento se marca una identidad con sus lugares de procedencia, referencian allí un clima similar y unas costumbres similares que trajeron consigo, usos de los bienes y servicios que ofrece el territorio y por unas prácticas sociales; la desterritorialización que García Canclini (como se citó en Nates, 2011) "entiende como esa pérdida de relación de la cultura con el territorio, la cual se da en un movimiento que puede permitir la reterritorialización" (p. 216).

Esta desterritorialización no fue total lo que facilitó una reterritorialización que buscó construir nuevas formas de relacionamiento de las comunidades entre sí y con el medio natural, fortaleciendo su postura política y reconocimiento como actores que inciden, efectivamente, en la nueva construcción del territorio que representan como su casa, el lugar donde caben y donde pueden vivir tranquilos. 
Desdeuna visión integradora del territorio, comolo propone Haesbaert (2011) los momentos o más bien procesos, ya que no son sucesos puntuales, corresponden al desarrollo secuencial de las dinámicas propias del entorno, como la territorialización, la desterritorialización y la reterritorialización están estrechamente relacionados con las dinámicas que se dan desde el territorio visto desde una óptica material de soporte y concreción de la vida, desde lo económico como fundamente de los usos que permite y que se dan al entorno, desde una óptica política vista como esa red de relaciones y de configuración de intereses y confrontaciones ocurridas por una misma porción de tierra y por su significado, desde una óptica de lo simbólico visto como esa experiencia subjetiva de sentirse pertenecer a un lugar de referencia y en donde se identifica con las practicas, los usos y las relaciones que allí se tejen.

Si desde la visión integradora del territorio propuesta por Haesbaert (2011), se indaga por la dimensión en la que se dio, en su momento, la desterritorialización de San Lucas, puede enfatizarse en la perspectiva política, ya que en ella se vislumbran las relaciones de poder y de control territorial, el autor propone, siguiendo los planteamientos de Deleuze y Guattari, al Estado como el mayor actor desterritorializador, desde su constitución gracias a la división de la tierra a través de la organización administrativa, agraria y habitacional, para el caso de San Lucas, además, puede retribuirse otras responsabilidades dado su ausencia real en el territorio, lo que facilitó el fortalecimiento de las estrategias de guerra de los grupos armados, generando vulnerabilidad en las comunidades campesinas mestizas y étnicas que allí habitan, podría decirse, desde el momento en el que se establece la unidad biogeográfica de San Lucas como ZRF de Ley 2 da en 1959, cuya determinación de terrenos baldíos de la nación, quizá se continuó asumiendo la no habitabilidad de comunidades campesinas, las mismas que ya estaban realizando su proceso de territorialización, incluso, antes o paralelo al establecimiento de la Ley. Una desterritorialización que si bien se fundamentó en una perspectiva política, influenció enormemente en la dinámica de vida de las comunidades desde lo económico (congelación de la economía local) y desde lo social y cultural (restricción de movilidad, amedrentamiento, asesinatos, retenciones, reclutamiento, destierro, pérdida de confianza), factor determinante para la "anulación" de la vida en su territorio, sin que ello implicase la "perdida de referentes de identidad con su territorio" que es el riesgo que expone Néstor García Canclini (como se citó en Haesbaert 2011).

El arraigo entonces se entiende como un vínculo de identidad con San Lucas, como el territorio que han apropiado y en el que se sienten cómodos y capaces de desarrollar sus vidas (Múnera, 2011). En este 
proceso interpretativo, conviene enfatizar la trascendencia del arraigo de las personas con este territorio, pues, a pesar de la imposibilidad de formalizar la tenencia de sus tierras y de las condiciones de marginalidad en las que aún viven, han tomado la decisión de regresar y reconfigurarlo a partir de nuevos tejidos sociales. $\mathrm{Y}$ ha sido el conflicto el que detonó esta nueva oportunidad de vivir en el territorio y su posibilidad de reconstruir política, social, cultural y económicamente las comunidades que lo habitan, según, en el entender de la comunidad, a este nuevo momento han llegado instituciones que acompañan el territorio restableciendo derechos como salud, educación, movilidad, alimento, vivienda, participación.

\section{Conclusiones}

Finalmente, San Lucas como territorio, reterritorializado es un escenario de nuevas oportunidades de entendimiento y de otras formas de relacionamiento entre comunidades, con el bosque, con las instituciones, con su cultura, con sus dinámicas económicas, políticas y sociales. Es imperioso saldar la deuda social histórica que el país tiene con este territorio, de ser reconocido, es necesaria la voluntad para una sustentabilidad que surja de las expectativas y capacidades de las comunidades. Esto ya es posible, pues, como puede verse, es un territorio con personas capaces de crear iniciativas colectivas con el objetivo de tener una vida digna en su territorio.

En la actualidad se dan otras relaciones marcadas por el retorno al territorio, porque sienten que es suyo, la expectativa de repoblar las veredas y de invitar a otras personas a volver, a construir mecanismos de información y participación ciudadana que promuevan el ingreso de actores institucionales, la cosmovisión cultural, de la necesidad de conservar y de integrar a sus prácticas de vida, el uso sostenible del bosque. Estos aspectos muestran resiliencia colectiva, que permite expresar lo sucedido, como parte de su memoria histórica, y de reconstrucción de su territorio.

El conflicto armado marca un momento crucial en la configuración territorial de las comunidades, pues ocasionó daños físicos, culturales, ambientales, psicológicos, con una profunda huella y un marcado temor a la repetición, lo que se ha expresado en la manera como se relacionan con el otro, con temor incluso con las personas con quienes vivían, en los caminos, con quienes construían comunidad. El conflicto produjo un territorio desterrado, pues un lugar territorializado por relaciones sociales configuradas fue despojado y se rompieron los lazos de confianzas, amistad, solidaridad, familiaridad pues ya no era un lugar seguro para vivir. 
Enesos momentos de crisis, también seescucharon voces de resistencia, pues algunos no quisieron dejar su tierra, y motivaron su repoblamiento. También fueron silenciados con la muerte y el desplazamiento, con la imposibilidad de ingresar alimentos y con la restricción de la movilidad. Esas resistencias fueron un acto político y material de confrontación simbólica de la comunidad hacia los actores violentos, y marcó la pauta para el regreso y de identificación de otras oportunidades para re-enlazar los vínculos antiguos y crear nuevos tejidos. Acudieron a su historia para encontrar lazos de cohesión en la organización comunitaria para participar y resistir, para recuperar y exigir la no repetición, para reivindicar derechos por la tierra, por la salud, por la educación, por el respeto a la vida que les permita vivir con dignidad.

\section{Referencias bibliográficas}

Acción Social. (2009). Caracterización de las reservas forestales de Ley 2/59. Recuperado de http:// restituciondetierras.gov.co/media/descarga.

Ángel Maya, A. (1997). Sociedad, Cultura y Medio Ambiente. Ciencia y Tecnología, 21(2), 12.

Ángel, D. (2012). La hermenéutica y los métodos de investigación en ciencias sociales. Revista de Estudios de Filosofía, 43.

Ángel, D. y Herrera, J. D. (2011). La propuesta hermenéutica como crítica y como criterio del problema del método. Revista de Estudios de Filosofía, (43), 9-29.

Arboleda, E. (2007). La frontera borrosa en la construcción conceptual y fáctica del habitar: relaciones centro periferia, caso sector San Lorenzo. Medellín, Colombia: Universidad Nacional de Colombia - sede Medellín.

BIORRED. (2014). Plan de Rehabilitación de la cuenca de la quebrada Villa en el municipio de El Bagre, Antioquia. Medellín: Jardín Botanico de Medellín.

CORANTIOQUIA. (2013). Plan de Ordenación Forestal: zona de reserva forestal del Río Magdalena Bajo Cauca y Nordeste de Antioquia, municipios de Zaragoza, Remedios, Segovia, El Bagre y Nechí. Sin publicar. Medellín: Corporación Autónoma Regional del Centro de Antioquia.

Echeverría, M.C. y Rincón, A. (2000). Ciudad de territorialidades. Polémicas de Medellín. Medellín, Colombia: Centro de Estudios del Hábitat Popular Cehap - Universidad Nacional de Colombia, Sede Medellín.

Fundación Ideas para la Paz (FIP). (2014). Dinámicas del conflicto armado en el Bajo Cauca antioqueño y su impacto humanitario. Recuperado de http://cdn.ideaspaz.org/media/ website/document/52efd828c4cbe.

Gaviria, B. (2014). Cartografías para la paz: una mirada crítica al territorio. En Cátedra Institucional Lasallista 2013 (pp. 45- 64). Bogotá: Universidad de La Salle.

Haesbaert, R. (2011). El mito de la desterritorialización: del "fin de los territorios" a la multiterritorialidad. México: Siglo XXI.

Herner, M. (2009). Territorio, desterritorialización y re-territorialización: un abordaje desde la perspectiva de Deleuze y Guattari. En: Huellas No. 13.

Herrera, J.D. (2009). La comprensión de lo social. Horizonte hermenéutico de las ciencias sociales. Bogotá: CINDE.

Imbach, A. (2012). Estrategias de vida: Analizando las conexiones entre la satisfacción de las necesidades humanas fundamentales y los recursos de las comunidades rurales. San José de Costa Rica: Geolatina Ediciones. 
Jimeno, M. (2016). Introducción. El enfoque narrativo. En Etnografías contemporáneas III: Las narrativas en la investigación antropológica (pp. 7-21). Bogotá: Centro de Estudios Sociales, Universidad Nacional de Colombia.

Ley 2 (1959), por el cual se dictan normas sobre economía forestal de la Nación y conservación de recursos naturales renovables. Diario Oficial 16/12.

Martínez, M. (2004). Ciencia y arte en la metodología cualitativa. México: Trillas.

Múnera, M. C. (2011). Construcción social del Hábitat: Más allá de una politica de producción de vivienda. Recuperado de http://construccionsocialdelhabitat.files.wordpress. com/2011/04/construccic3b3n-social-del-hc3a1bitat.pdf

Nates, B. (2010). La territorialización del conocimiento: Categorías y clasificaciones culturales como ejercicios antropológicos. Barcelona, España: Antrhopos Editorial.

Nates, B. (2011). Soportes teóricos y etnográficos sobre conceptos de desarrollo (209 -220). Revista Co-herencia, 8 (14).

Ríos, G. y Sanclemente, S. (2014). Gestión de las Reservas Forestales Nacionales de la Ley 2 de 1959: problemas y perspectivas en la relación entre bosques y gente. INFORME PREVENTIVO No. 049-2014. Medellín, Caldas: Procuraduría Delegada para Asuntos Ambientales y Agrarios.

Sánchez, N. (2014). Cartografías para la paz: una mirada crítica al territorio. En Cátedra Institucional Lasallista 2013 (pp. 15- 22). Bogotá: Universidad de La Salle.

Sosa, M. (2012). ¿Cómo entender el territorio?. Ciudad de Guatemala: Editorial Cara Parens de la Universidad Rafael Landívar.

Unidad para la Atención y Reparación Integral a las Victimas (UARIV). (2014). Acta de caracterización de los daños colectivos, sujeto de reparación colectiva comunidad campesina del corregimiento de Puerto López, municipio de El Bagre, Bajo Cauca - Antioquia (documento de trabajo). Medellín: Unidad para la Atención y Reparación Integral a las Victimas, Dirección Territorial Antioquia.

Vélez, N., Correa, I.C. y Ríos, G. (2010). Deforestación, ordenación forestal y campesinado. Medellín, Colombia: Corantioquia.

Wilches Chaux, G. (2006). Brújula, bastón y lámpara. Para trasegar los caminos de la educación ambiental. Bogotá, Colombia: Ministerio de Ambiente, Vivienda y Desarrollo Territorial. 